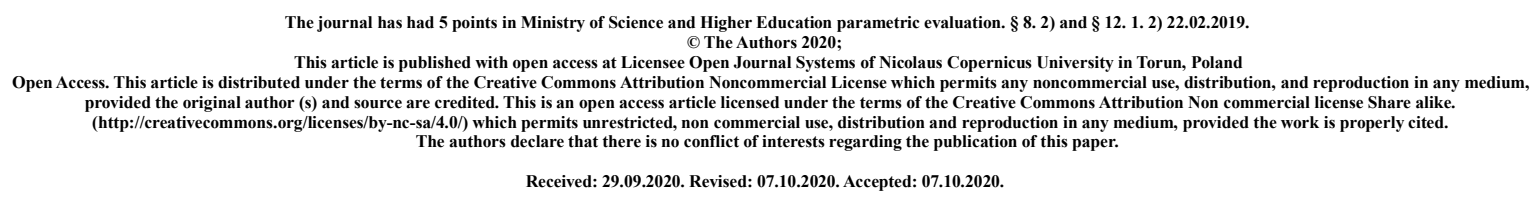

\title{
Acromegaly - dealing with an uncooperative patient
}

Michał Obel ${ }^{1}$, Ewelina Mazurek ${ }^{2}$, Adrian Kuś3 ${ }^{3}$, Małgorzata Szypłowska $^{3}$, Adrianna Gorecka ${ }^{3}$, Bartłomiej Zaremba ${ }^{3}$

1. Student Scientific Association at the Department of Endorinology of the Medical University of Lublin

2. Collegium Medicum in Bydgoszcz, Nicolaus Copernicus University in Toruń

3. Student Scientific Associationat at the Department of Epidemiology and Clinical Research Methodology of the Medical University of Lublin

Supervisor: $\mathrm{PhD}$ Ewa Obel ${ }^{4}$

4. Department of Endorinology of the Medical University of Lublin

Corresponding author: Michał Obel, michalobel3@gmail.com

ORCID ID :

Michał Obel https://orcid.org/0000-0003-1237-8732

Ewelina Mazurek https://orcid.org/0000-0002-5687-313X

Adriań Kuś https://orcid.org/0000-0002-6624-5743

Małgorzata Szypłowska https://orcid.org/0000-0001-9811-8776

Adrianna Gorecka https://orcid.org/0000-0003-1977-712X

Bartłomiej Zaremba https://orcid.org/0000-0002-3255-2745 


\begin{abstract}
Introduction: Acromegaly is a chronic disease resulting from increased secretion of growth hormone. The main reason of elevated GH concentration is pituitary adenoma that originates from somatotropic cells. As a consequence, several changes in the organism appear such as progressive deformation of the skeleton with enlargement of the skull, hands and feet, growth of soft tissues, bones and internal organs as well as many other systemic complications which are responsible for increased mortality in untreated patients.
\end{abstract}

Case report: A 60-year-old patient was diagnosed with acromegaly due to the pituitary macroadenoma and associated hypopituitarism in the thyroid and gonadotropic axis 4 years ago. The disease was suspected in April 2016 by a rheumatologist, and then confirmed on the basis of hormonal tests in the Endocrinology Clinic (IGF1 - $754.7 \mathrm{ng} / \mathrm{ml}, \mathrm{N}$ : 77-224; GH $2.51 \mathrm{ng} / \mathrm{ml}$, no inhibition in OGTT). The imaging examination revealed a pituitary macroadenoma with dimensions of $17 \times 15 \times 19 \mathrm{~mm}$. The medical history revealed the characteristic symptoms of acromegaly like enlargement and deformation of the fingers, enlarged nose, excessive sweating and headaches for the last 12 years. There have been several studies investigating the complications of acromegaly that found abnormalities in the cardiovascular system, metabolic disorders (dyslipidemia, abnormal fasting glycaemia), arthropathies, sigmoid polyps and nodular goiter. Due to the patient's lack of consent to the surgical intervention, treatment with a somatostatin analogue was introduced. During 2-year therapy, the normalization of IGF-1 concentration was not achieved. In October 2018 patient completely abandoned therapy with somatostatin analogue. In 2019 the lack of control of acromegaly was confirmed. During hospitalization in 2020 the uncontrolled acromegaly was stated once again. The patient still does not consent to the surgical procedure to remove pituitary macroadenoma, however, he agreed for systematic re-treatment with a somatostatin analogue.

Conclusions: Isolated pharmacological treatment doesn't always allow for sufficient control of an illness. Effective treatment of acromegaly should consist of surgery as well as conservative treatment. The introductinon of both 2 nd generation analogues and GH receptor antagonists in therapeutic programs makes effective pharmacological treatment possible. 
Key words: Acromegaly, pituitary macroadenoma

\section{Introduction:}

Acromegaly is a rare condition caused by excessive secretion of growth hormone and secondarily elevated levels of insulin-like growth factor 1 (IGF-1) for which changes in the external appearance, metabolic disorders and the development of systemic complications are characteristic[1]. The most common cause (99\% of cases) of acromegaly is the autonomic excessive secretion of GH by the pituitary adenoma. Rarely, the reason could be secretion of somatoliberin by neuroendocrine tumors[2]. Pituitary tumors secreting growth hormone are usually macroadenomas located in the lateral wings of the pituitary gland and may invade adjacent structures [4]. Large tumors, in addition to excessive hormone secretion, can also cause a "mass" effect in the form of visual field disturbances - either by compression on the optic chiasm or headaches caused by increased intracranial pressure. In addition, the pressure caused by the growing tumor on the healthy pituitary flesh can lead to a deficiency in the secretion of other hormones [3]. The annual incidence rate of acromegaly is 3.3 people per million and the estimated prevalence rate is 40 to 130 people per million. It occurs with the same frequency in both sexes, and the peak of diagnoses falls on the 4-5th decade of life[5]. The most characteristic general symptoms are enlargement of hands, feet, facial skeleton (nose, mandible, frontal sinuses) and tongue. Additionally, there is a thickening of facial features, swelling of soft tissues, enlargement of internal organs and increased sweating. Symptoms of acromegaly can affect any organ[1]

The diagnosis of active acromegaly is based on the presence of clinical symptoms and simultaneously increased IGF-1 and GH secretion [6].

The mainstay of acromegaly treatment is surgical removal of the tumor through the sphenoid sinus. Another possibility is the use of pharmacotherapy in a form of somatostatin analogues or GH receptor antagonists. However, complementary therapy with the use of stereotaxic radiotherapy (alternatively the gamma knife) is required [7].

Case report: A 60-year-old patient was diagnosed with acromegaly due to the pituitary macroadenoma and associated hypopituitarism in the thyroid and gonadotropic axis 4 years ago. The disease was suspected in April 2016 by a rheumatologist, and then confirmed on the basis of hormonal tests in the Endocrinology Clinic (IGF1 - $754.7 \mathrm{ng} / \mathrm{ml}, \mathrm{N}$ : 77-224; GH $2.51 \mathrm{ng} / \mathrm{ml}$, no inhibition in OGTT). The imaging examination revealed a pituitary macroadenoma with dimensions of $17 \times 15 \times 19 \mathrm{~mm}$. The medical history revealed the characteristic symptoms of acromegaly like enlargement and deformation of the fingers, enlarged nose, excessive sweating and headaches for the last 12 years. Due to the suspicion of the presence of metal filings in the muscle (not confirmed in the later X-ray image), the 
patient was disqualified from the MRI examination. The CT examination revealed a higher dense area in the pituitary gland ( $8 \mathrm{~mm}$ in the diameter) which could correspond to pituitary microadenoma. The patient did not consent to the surgery. In July 2016 the therapy with somatostatin analogue - octreotide (Sandostatin LAR $20 \mathrm{mg}$ every 4 weeks) was implemented. In March 2017 octreotide was changed to the second analog of somatostatin of the first generation - lanreotide (Somatulin Autogel $120 \mathrm{mg}$ every 4 weeks). At the same time, substitution treatment with L-thyroxine (Euthyrox) was introducted. During hospitalization in September 2017 no effective control of acromegaly was demonstrated (IGF1 - $523.4 \mathrm{ng} / \mathrm{ml}$, GH - $3.5 \mathrm{ng} / \mathrm{ml}$, no inhibition in OGTT),. However, effective hypothyroidism substitution and normal pituitary function in other tropic axes were confirmed. Due to the lack of effective control of acromegaly (September 2017) the surgery was proposed, yet again rejected by the patient.

During the 2-year therapy, the normalization of IGF-1 concentration was not achieved (IGF-1 concentrations remained in the range of 523-714 $\mathrm{ng} / \mathrm{ml}$ ). The patient took the drug irregularly, and starting from October 2018 he completely quit therapy. In a study conducted in December 2018 the IGF-1 concentration was $1050 \mathrm{ng} / \mathrm{ml}$ and the $\mathrm{GH}$ concentration stood at $4.64 \mathrm{ng} / \mathrm{ml}$. The MRI of the pituitary gland was performed and proceeded without any complications. Within the Turkish saddle, an oval focal lesion was found filling the Turkish saddle and the suprasellar area, clearly supporting the optic junction, remaining in a direct contact with the medial walls of the cavernous sinuses. The cerebral funnel was also affected. A lesion of the pituitary macroadenoma size $17 \times 15 \times 19 \mathrm{~mm}$ was diagnosed. During subsequent hospitalizations, complications of acromegaly were found in the form of impaired fasting glycaemia and dyslipidemia. Additionally, arterial hypertension, chronic ischemic heart disease and mild mitral, aortic and tricuspid valve regurgitation have been demonstrated. In the ECG recorded by Holter additional stimulations of supraventricular origin were recorded. In the diagnostic process nodular goiter, gallbladder stones and benign prostatic hyperplasia were confirmed. Three polyps were found and removed during the colonoscopy. In addition, osteoarthritis of the hip joints and spine has been demonstrated. Due to the patient's reported headaches, dizziness and periodic photophobia, an EEG test was performed. There was an abnormal recording with changes in the fronto-parieto-temporal area.

During hospitalization in March 2019 active acromegaly was stated again (IGF-1: $908 \mathrm{ng} / \mathrm{ml}$, GH: $4.64 \mathrm{ng} / \mathrm{ml}$ ). Taking into consideration almost three-year period from the diagnosis of the disease and the lack of response to the applied treatment with the 1st generation analogue, the treatment with a second-generation somatostatin analogue (pasireotide) was proposed. However, the patient did not start treatment and did not come for consultations at the Endocrinology Clinic.

On the next hospitalization in September 2020 once again an active acromegaly was confirmed (IGF-1: $817 \mathrm{ng} / \mathrm{ml}, \mathrm{GH}: 6.20 \mathrm{ng} / \mathrm{ml}$ ). The patient still does not consent to removal of the pituitary macroadenoma, however, he agreed to systematic re-treatment with a somatostatin analogue after a discussion about complications of untreated acromegaly was conducted.

Discussion: Although the symptoms of acromegaly are characteristic, the diagnosis is usually made only after several or even several years of its duration [1]. The change in facial features, 
enlargement, hands and feet usually develops slowly and imperceptibly to the patient. Bibliographic data show that only $10-15 \%$ of people with acromegaly turned to a doctor concerned about the change in appearance. The symptoms of acromegaly are most often associated with systemic complications or local tumor growth [8]. About $40 \%$ of acromegaly patients are initially diagnosed by an internist, the remaining cases are diagnosed, inter alia, by a rheumatologist[9]. Our patient had symptoms for 12 years. The patient complained more of headaches and dizziness or night sweats than noticed changes in his appearance. He treated bone and joint pain as symptoms of aging. The disease was suspected by a rheumatologist.

The diagnosis of active acromegaly is based on the presence of signs and symptoms and increased secretion of both IGF-1 and GH. Patients with signs suggestive of acromegaly should undergo a screening IGF-1 assay. If the levels are above the upper limit of normal (for age and sex), GH suppression in oral glucose tolerance test (OGTT) after administration of 75 $\mathrm{g}$ of glucose is recommended. Active acromegaly is diagnosed when the IGF-1 level is increased and GH secretion in OGTT is not suppressed below $1.0 \mu \mathrm{g} / \mathrm{L}$. . A random GH level below $1.0 \mu \mathrm{g} / \mathrm{L}$ rules out active acromegaly [6]. Following biochemical diagnosis, contrast enhanced magnetic resonance imaging (MRI) of the sellar region is required to assess tumor size, localization and invasiveness. Gadolinium enhancement should however be used with caution or be avoided in patients with renal impairment. If MRI is contraindicated or unavailable, pituitary computerized tomography should be performer [11]. In view of the clinical symptoms, a hormonal diagnosis was performed, in which the following results were obtained: IGF-1 - $754.7 \mathrm{ng} / \mathrm{ml}$; $\mathrm{n}$ : 77-224, GH - $2.51 \mathrm{ng} / \mathrm{ml}$ and no inhibition in OGTT was found. Due to the presence of metal filings in the patient's lower leg, he was disqualified from the MRI examination. Initially, the CT examination of the pituitary gland revealed a higher dense area, $8 \mathrm{~mm}$ in diameter. However, at a later stage, due to the lack of hormonal control, it was decided to perform an MRI examination. The examination was performed without complications. A lesion of the pituitary macroadenoma with dimensions $17 \times 15 \times 19 \mathrm{~mm}$ was described. MRI is the preferred method of imaging the hypothalamic pituitary system.

The main goal of acromegaly treatment it to normalise the GH and IGF-1 secretion and thus improve life expectancy and quality of life. Tumour removal or significant reduction in its volume, which should reduce symptoms related to its expansion, is the secondary goal. Both goals can be achieved with surgical treatment, pharmacotherapy, or, less frequently, radiotherapy [6].

The patient never consented to surgery to remove the pituitary macroadenoma, however, he agreed to be treated with pharmacotherapy.

Medical treatment options for these patients include somatostatin analogues (octreotide, lanreotide, and pasireotide), GH receptor antagonists (pegvisomant), or oral dopamine agonists (cabergoline). The treatment goals for acromegaly are to reduce the tumor size and to maintain GH and IGF-1 within normal ranges as well as to improve the clinical symptoms and signs of acromegaly. When surgical treatments are unavailable or are refused by patients, medical treatments may be considered as primary therapy [5].

During the 2-year therapy, the normalization of IGF-1 concentration was not achieved. This may have been due to the lack of adherence on the part of the patient. The lack of cooperation could result from recurrent depressive disorders with which the patient had been suffering from 2012. The patient took the drug irregularly, and from October 2018. he quit therapy. On 
the next hospitalization in September 2020 once again an active acromegaly was confirmed. He agreed to systematic re-treatment with a somatostatin analogue after a discussion about complications of untreated acromegaly was conducted.

Conclusions: Isolated pharmacological treatment doesn't always allow for sufficient control of an illness. Effective treatment of acromegaly should consist of surgery as well as conservative treatment. The introduction of both 2 nd generation analogues and GH receptor antagonists in therapeutic programs makes effective pharmacological treatment possible.

\section{Bibliography}

1. Ruchała M., Szczepanek-Parulska E., Komorska-Piotrowiak E. Diagnostics and treatment of acromegaly. OncoReview 2011/vol.1/Nr.4/240-247

2. Zgliczyński W., Witek P., Zdunowski P. (2011). Guzy przysadki [Pituitary tumor] W: W. Zgliczyński (red.) Endokrynologia część 1 Wielka Interna.

3. Bolanowski M., Kałużny M., Jawiarczyk-Przybyłowska A., SomatotropinomaAkromegalia W: A. Milewicz (red.) Endokrynologia Kliniczna tom 1. 157-162

4. Bolanowski M. Guzy przysadki [Pituitary tumor] (2012) W: A. Milewicz (red.) Endokrynologia Kliniczna tom 2. (s. 148-150)Wrocław

5. Sang Ouk Chin, Cheol Ryong K, Byung Joon Kim, Sung-Woon K, Kyeong H.P, Kee H.S, Seungjoon O, Hyun K.Y, Eun J.L, Jung M.L, Jung S.L, Jung H.K, Kwang J.K, Heung Y.J, Dae J.K, Kyung A.L, Dong J.L, Dong Y.S, Se H.K, Min J.K, Ha Y.K, Jin H.J Dong S.K Chong. H.K Medical Treatment with Somatostatin Analogues in Acromegaly: Position Statement Endocrinol Metab (Seoul). 2019 Mar; 34(1): 53-62

6. Bolanowski M., Ruchała M., Zgliczyński W., Kos-Kudła B., Hubalewska-Dydejczyk A., Lewiński A. Diagnostics and treatment of acromegaly - updated recommendations of the Polish Society of Endocrinology. Endokrynologia Polska Vol 70/ Nr 1/ 2019/ 11-18

7. Bolanowski M., Ruchała M., Zgliczyński W., Kos-Kudła B., Bałdys-Waligórska A., Zieliński G., Bednarczuk T., Hubalewska-Dydejczyk A., Kamiński G., Bogdan M., Daroszewski J., Waśko R., Lewiński A. Acromegaly- a novel view of the patient. Polish proposal od diagnostic and therapeutic procedurę in the light of recent reports. Endokrynologia Polska Vol 65/ Education supplement I/ 2014/31-37

8. Lucio V., Clarice F.V., Ruy L.,Raissa L., Naves L. Acromegaly: clinical features at diagnosis Pituitary 2017 Feb;20(1):22-32. doi: 10.1007/s11102-016-0772-8

9. Melmed S (2006) Acromegaly. N Engl J Med 355 (24): 2558-2573

10. Jallad R.S., Bronstein M.D., Acromegaly in the elderly patient Arch. Endocrinol. Metab. vol.63 no.6 São Paulo Nov./Dec. 2019 Epub Jan 10, 2020 638-645 